\section{Messgröße, intensive und extensive}

C. Vidal

Landeskriminalamt Niedersachsen, Dezernat 53 „Chemie“,

Hannover, Deutschland

Englischer Begriff intensive and extensive quantity
Definition Intensive Messgrößen bleiben bei einer Größenänderung des Systems konstant (z. B. Temperatur, Druck), extensive Messgrößen ändern sich mit der Systemgröße (z. B. Masse, Stoffmenge, Länge, Volumen).

\section{Literatur}

Atkins PW, de Paula J (2006) Physikalische Chemie, 5. Aufl. Wiley$\mathrm{VCH}$, Weinheim, S 5 